\title{
O MUNDO NECESSITA DE POESIA: A LÍRICA E A SOCIEDADE NA OBRA DE GILKA MACHADO
}

\author{
DiEgo GRANDO* \\ JULIANA MAFFEIS
}

\section{Resumo}

Analisamos o sujeito lírico na obra de Gilka Machado em dois momentos: nos poemas "Ser mulher...", publicado em sua obra de estreia, Cristais partidos, de 1915, e "O mundo necessita de poesia”, que integra sua última obra, Sublimação, de 1938. Ao observarmos as relações pertinentes entre lírica e sociedade, exploramos as questões sociais e estéticas que orientaram a trajetória da poeta. Dessa forma, ampliamos a pesquisa sobre a obra de Gilka Machado, contribuindo para o resgate da poeta na história da literatura brasileira.

Palavras-chave: Poesia. Gilka Machado. Autoria feminina.

"Sonhei ser útil à humanidade. Não consegui, mas fiz versos. Estou convicta de que a poesia é tão indispensável à existência como a água, o ar, a luz, a crença, o pão e o amor." (MACHADO, 2017, p. 17)

Mulher, negra e de origem pobre, Gilka da Costa de Melo Machado nasceu no Rio de Janeiro, em março de 1893, e viveu até os 87 anos, vindo a falecer em dezembro de 1980. A disposição para as artes parece ser uma tradição familiar. Seu avô materno, Francisco Moniz Barreto, e seu pai,

Professor colaborador do Programa de Pós-Graduação em Letras da Pontifícia Universidade Católica do Rio Grande do Sul/PUCRS, Porto Alegre, Rio Grande do Sul, Brasil. Bolsista do Programa Nacional de Pós-Doutorado (PNPD/Capes).

E-mail: grando.diego@gmail.com Orcid iD: https://orcid.org/0000-0001-8907-8864

** Doutoranda em Letras - Escrita Criativa na Pontifícia Universidade Católica do Rio Grande do Sul/PUCRS, Porto Alegre, Rio Grande do Sul, Brasil.

E-mail: maffeisjuliana@gmail.com Orcid iD: https://orcid.org/0000-0002-6962-4116 
Hortêncio da Gama Souza Melo, foram poetas repentistas, e sua mãe, Teresa Costa, foi uma atriz de renome, motivo de grande admiração para a poeta.

A imersão em uma atmosfera artística contribuiu para que Gilka Machado driblasse os preconceitos racistas e misóginos e iniciasse sua carreira com a publicação de poemas em revistas. Ainda antes de estrear em livro, ela proferiu uma conferência denominada $A$ revelação dos perfumes, no Rio de Janeiro, em 1916. Seus dois primeiros livros, Cristais partidos (1915) e Estados de alma (1917), logo foram reunidos em Poesias (1918). Gilka Machado seguiu publicando poemas em revistas, como Souza Cruz e Festa, e lançou, em 1922, a obra Mulher nua. Em 1928, publicou Meu glorioso pecado e, na sequência, Carne e alma (1931), Sublimação (1938) e Meu rosto (1947), sendo este último uma coletânea de suas composições. Ao completar cinquenta anos de sua estreia com Cristais partidos, a poeta editou Velha poesia (1965), antologia de sua produção, incluindo também textos inéditos. Mais recentemente, em 2017, toda a sua obra foi reeditada e lançada pelo Selo Demônio Negro, após mais de duas décadas fora de catálogo.

Considerada a primeira poeta a publicar poesia erótica no Brasil, em um momento em que mulheres nem mesmo conseguiam publicar seus escritos, Gilka Machado enfrentou uma série de dificuldades para manter uma produção literária ativa em um cenário habitado por homens, em sua maioria brancos e com alto poder aquisitivo. Em seus versos, Gilka Machado trouxe temas que abordam os desejos, os traumas, as paixões e a sexualidade feminina para dentro da poesia brasileira e, como esperado, a crítica reagiu instantaneamente.

Gilka Machado incomodou os escritores e críticos que habitavam o cenário monótono e homogêneo da literatura brasileira da época. Rui Barbosa (1849-1923), por exemplo, se perguntava “[...] como seria possível conciliar o espírito das senhoras de boa sociedade com o espírito de uma poetisa que tem o mau gosto de escrever essas coisas plebeias" (MACHADO, 2017, p. 38). No jornal A imprensa, dirigido por José do Patrocínio Filho, foi publicada uma caricatura em que a escritora aparece 
vestindo uma saia esvoaçante junto ao verso "eu sinto que nasci para o pecado", retirado do soneto "Reflexões", de sua autoria, porém, em um contexto totalmente alterado. Em 1930, Afrânio Peixoto relata a Humberto de Campos sua decepção ao se encontrar com Gilka, descrevendo-a como "uma pequena mestiça sombria”, e não a "jovem mulher branca, atraente, chamando a atenção” que ele esperava, declarando uma visão de extremo machismo e racismo (MACHADO, 2017, p. 34).

Apesar das incontáveis críticas, muito mais à sua pessoa do que aos seus escritos, houve quem reconhecesse seu talento literário. Lima Barreto, Olavo Bilac e Nelson Rodrigues declararam publicamente seu encantamento pelos versos de Gilka Machado. Jorge Amado, inclusive, fez questão de que a poeta se candidatasse a uma cadeira na Academia Brasileira de Letras quando a instituição abriu vagas para mulheres na década de 1970, porém ela não levou a candidatura adiante. Bem antes, em 1933, Gilka Machado havia sido eleita pela revista O Malho a melhor poeta brasileira, em votação realizada com cerca de 200 intelectuais da época.

Ainda que com escritores renomados a seu favor, existia um aparente cuidado para lidar com a obra de Gilka Machado. Era comum os poucos autores ou críticos da época que se dispunham a comentar sua poesia serem tocados por uma espécie de receio moral, que tensionava a relação entre vida e obra: para evitar que a repercussão do seu trabalho pudesse significar a aprovação da conduta "imoral" de uma mulher que escrevia versos enquanto deveria estar se dedicando à casa, aos filhos, ao marido e às demais "atribuições femininas", era preciso ressaltar uma vida "correta" para que se pudesse validar sua obra, como fez Humberto de Campos, ao elogiar seus versos afirmando que ela era “[...] a mais virtuosa das mulheres e a mais abnegada das mães” (MACHADO, 2017, p. 40).

Para Paz (1994, p. 12), “[...] a relação entre erotismo e poesia é tal que se pode dizer, sem afetação, que o primeiro é uma poética corporal e o segundo uma erótica verbal", porém, o tema do erotismo contido na poesia de Gilka Machado pode ser considerado seu trunfo e sua maldição, uma vez que a crítica não conseguia compreender o conteúdo de sua 
obra, tampouco como ela poderia ter sido escrita por uma mulher. Sem perceber o distanciamento do sujeito lírico na escrita da poesia, "muitos acreditavam que ela fazia o que escrevia nos poemas, que era a 'messalina hedionda' de seus versos, colocando-a como um mau exemplo de mulher”, lamenta a organizadora da recente reedição da obra de Gilka Machado, Jamyle Rkain, em entrevista concedida a Amanda Massuela, publicada na revista Cult (2017).

A confusão que nasce da crença de que o sujeito lírico e o poeta possuem a mesma voz tem suscitado discussões em todos os tempos. Sendo a lírica o gênero literário do sujeito e da subjetividade, quando as palavras são enunciadas por um sujeito lírico ou empírico? A linguagem poética pode surgir através da aurora da palavra, segundo Ricouer (1978, p. 321), pois o sujeito lírico, ao se constituir como imagem, “[...] torna-se um novo ser da nossa linguagem, exprime-nos ao tornar-nos naquilo que ela exprime; ela é um devir da expressão".

Em uma entrevista concedida a Gotlib (2016), a poeta, que abandonou a carreira literária aos 45 anos, declarou que estaria farta de não conseguir se expressar como gostaria, cansada daquilo que a exposição pública lhe havia causado: "Eu tomei enjôo - da poesia não, mas do ambiente” (MACHADO, 2017, p. 48). Em 1979, a poeta relembrou os insultos a que seus filhos foram submetidos por serem filhos de uma "mulher imoral" como mãe. Tal adjetivo a acompanhou durante grande parte da sua trajetória, e esse entendimento foi criado porque Gilka Machado ousou explorar um “[...] território então proibido à mulher” (GOTLIB, 2016, p. 77).

Podemos pensar que o território proibido é, sim, a poesia, mas principalmente quando o corpo da mulher, sua sexualidade, sua vontade e seu desejo são considerados motivos para sua própria expressão. Os poemas de Gilka Machado documentam uma situação de impossibilidade sobre tomada de decisões, inclusive, sobre questões que apenas a ela pertenciam. Quando falamos em território, entendemos que nesse local exista um discurso específico para que os habitantes desse espaço possam se comunicar. Aqui, precisamos esclarecer que a palavra discurso 
está relacionada à noção que Foucault (2007) traz ao vocábulo, que corresponde a um sistema que estabelece a estrutura de um determinado imaginário social, pois fala - também - de poder e controle.

Se todo discurso representa uma forma de poder, consequentemente os discursos que permeiam qualquer campo social são cercados por uma série de disputas, rivalidades e jogos de poder. Podemos pensar, então, que a disposição de manter a ordem dominante, ou a ordem do discurso, da parte de um determinado grupo que possui uma série de privilégios sociais (BOURDIEU, 1996), e o controle discursivo sobre a expressão da sexualidade feminina, no início do século XX, era ainda mais explícita do que nos dias de hoje, ao passo que a poesia de Gilka Machado e seu discurso sobre a subjetividade das mulheres podem ter representado uma espécie de ameaça a essa ordem.

Ao apresentar um sujeito lírico ativo em afirmar seu desejo, não apenas ao que corresponde à sexualidade, mas as suas vontades e anseios perante seu lugar na sociedade, a poesia de Gilka Machado convida o leitor a avaliar o discurso social por meio do próprio objeto poético. Adorno (1993) afirma que a referência ao social não deve levar a leitura para fora da obra de arte, mas sim para suas profundezas. Dessa forma, o filósofo estabelece que "[...] um poema não é a mera expressão de emoções e experiências individuais", mas, ao contrário, "estas só se tornam artísticas quando, justamente em virtude da especificação que adquirem ao ganhar forma estética, conquistam sua participação no universal" (ADORNO, 1993, p. 65).

Para compreendermos a lírica, tomamos como base as reflexões de Hegel (RAMOS, 1986), para quem, na lírica, o mundo objetivo, em contato com a consciência individual, é penetrado pela interioridade. Assim, lírica é a expressão da interioridade, sem que isso signifique apenas a voz individual. Para Adorno (1993), o sujeito que ganha voz na lírica é um sujeito que se determina e se exprime como oposto ao coletivo, à objetividade. Dessa forma, o sujeito lírico acabou perdendo a unidade com a natureza e agora se empenha em restabelecê-la pelo mergulho no próprio eu (ADORNO, 1993). 
Podemos pensar que o poema é um elemento que já possui um dado histórico e uma atitude crítica em sua própria composição. Logo, tratemos de buscar redescobrir o anseio histórico-social da obra, agora, através de um "mergulho" na própria obra. Adorno (1993) chamou esse movimento de "análise imanente", que significa tomar o próprio poema como ponto de partida, pois somente dessa forma conseguiremos acessar as profundezas de um objeto estético.

Após conhecer a trajetória de Gilka Machado, é difícil dissociar sua obra das questões que envolvem a sociedade, ou, ainda, interpretar seu sujeito lírico como uma voz totalmente distante daquela que fala com a sua gente e atravessa seus poemas de forma intensa, como a existência da própria autora. Todavia, é desnecessário que sejamos radicais para distinguir tais aspectos que podem, sim, uma vez ou outra, serem encontrados em algum discurso. Para Sabato (1983, p. 79), “[...] é fatal que, de alguma forma, a arte esteja relacionada com a sociedade, já que a arte é feita pelo homem, e o homem (ainda que seja um gênio) não está isolado: vive, pensa e sente em relação à sua circunstância”.

Pensando, então, em como o sujeito lírico de Gilka Machado incorpora as questões sociais em sua obra, analisaremos algumas das imagens construídas no poema "Ser mulher...", publicado em sua obra de estreia, Cristais Partidos, de 1915. Nessa obra, os motivos estéticos e ideológicos compreendem o erotismo a partir de um ponto de vista feminino, pouco encontrado na história da literatura brasileira. O erotismo de Gilka Machado se estende a problemas da cultura patriarcal, com grande zelo pelas formas fixas, como o soneto, utilizando a métrica e o ritmo para compor poemas com uma sonoridade bastante marcada, demonstrando seu conhecimento sobre a linguagem poética. Talvez um de seus poemas mais conhecidos, "Ser Mulher..." descreve a condição feminina na sociedade.

Ser mulher, vir à luz trazendo a alma talhada para os gozos da vida; a liberdade e o amor; tentar da glória a etérea e altívola escalada, na eterna aspiração de um sonho superior... 
Ser mulher, desejar outra alma pura e alada

para poder, com ela, o infinito transpor;

sentir a vida triste, insípida, isolada,

buscar um companheiro e encontrar um Senhor...

Ser mulher, calcular todo o infinito curto

para a larga expansão do desejado surto,

no ascenso espiritual aos perfeitos ideais...

Ser mulher, e, oh! atroz, tantálica tristeza!

ficar na vida qual uma águia inerte, presa

nos pesados grilhões dos preceitos sociais!

(MACHADO, 2017, p. 131)

Ao observar o poema, podemos detectar a dimensão crítica na voz do sujeito lírico: a partir de um jogo de antíteses, o soneto parte da ânsia pela liberdade (estrofe 1), passa pela busca por um companheiro (estrofes 2 e 3) e chega, finalmente, à frustração de encontrar, nessa mesma figura, um senhor com $S$ maiúsculo, a quem necessita servir, retomando a ideia de que a mulher somente pode habitar o mesmo território de um homem quando o discurso deste puder demonstrar seu poder e superioridade para com ela (estrofe 4).

Outro aspecto a ressaltar é o uso das reticências, no título e em outros três versos, que também contribui para indicar a situação do sujeito lírico: uma figura hesitante, indecisa e insatisfeita com as condições impostas. A exclamação surge na última estrofe, quando, após hesitar durante todo o poema, o sujeito chega à conclusão de que ser mulher é "ficar na vida qual uma águia inerte, presa / nos pesados grilhões dos preceitos sociais!”. Podemos pensar na imagem da águia, ave de rapina de grande porte, conhecida por ser exímia predadora e bastante usada como metáfora para caracterizar força e perspicácia. Para Valéry (1991, p. 4), uma metáfora é capaz de marcar “[...] um tateamento, uma hesitação entre várias expressões de um pensamento"; aqui, quando surge ao lado do adjetivo "inerte", faz com que percebamos toda a qualidade de uma 
palavra sendo anulada por outra, assim como essa mulher de grande potencial sendo aprisionada para servir a um homem.

Há também, no poema, uma referência a Tântalo, figura mitológica que recebeu um castigo e, desde então, não pode saciar sua fome nem sua sede. A expressão usada no poema se refere ao sofrimento daquele que deseja algo aparentemente próximo, porém inalcançável. Esse parece ser o suplício em que se encontra o sujeito desejante do poema, que reflete o quanto ser mulher poderia guardar "os gozos da vida; a liberdade e o amor", mas a condição em que ela se encontra impossibilita todo sentimento dessa ordem e apenas lhe faz carregar o peso dos "grilhões dos preceitos sociais".

Apesar de o sujeito lírico representar uma mulher que sofre, em uma situação íntima e individual, é pertinente pensar quantas outras puderam se identificar com esse mesmo contexto de opressão, cabendo aqui o sentido universal que perpassa a obra de Gilka Machado. Para Staiger (1975), o caráter íntimo da poesia sugere que o sujeito lírico configure e exprima a imagem de seu mundo interior interpretada por uma rejeição radical da sociedade que não permite a realização dos sonhos, dos seus verdadeiros desejos.

Para Paz (1994, p. 11), a poesia é uma espécie de "testemunho dos sentidos", pensando que "[...] suas imagens são palpáveis, visíveis e audíveis". Sendo o campo poético também um campo imagético, ao criar uma relação que permite que o leitor experimente muitas das sensações do texto ao se perceber naquele mesmo estágio, em um processo de identificação imediata, o poema acaba por gerar uma mesma disposição anímica entre os sujeitos. Tal disposição, cunhada assim por Staiger (1975), representa esse momento de conexão entre poema e leitor que vai designar o "um-no-outro", quando a realidade lírica é apreendida diretamente, "melhor que qualquer intuição ou qualquer esforço de compreensão” (p. 59).

Para pensar sobre outra realidade lírica, mas dentro da mesma vertente, debrucemo-nos brevemente sobre Sublimação (1938), essa que pode ser considerada a última publicação da autora, pois depois dela 
poucos poemas inéditos foram submetidos às duas reedições que foram lançadas, Meu rosto (1947) e Velha poesia (1965). A escolha dessa obra é simbólica no que diz respeito à intenção poética atribuída ao seu último livro, como se tal discurso fosse, de fato, aquele que a poeta gostaria de deixar ao mundo.

Podemos pensar que Sublimação apresenta algumas diferenças em relação ao restante da sua obra: ainda que muitos poemas tragam um sujeito lírico intimista, com o olhar voltado para temas relacionados à sexualidade e ao corpo da mulher, o livro apresenta uma maior força para as questões da sociedade, valendo-se de uma linguagem mais simples, livre da rigidez das formas fixas e do léxico apurado. Porém, tais características desse outro momento de Gilka Machado não podem ser usadas para acusá-la de uma poesia displicente, como se a autora estivesse abdicando da qualidade estética de seus escritos anteriores, pois, pelo contrário, 23 anos depois da publicação de seu primeiro livro, a poeta demonstra maturidade, autoconhecimento e firmeza em seus ideais sociais e estéticos.

O sujeito lírico de Sublimação se mostra, sim, menos intimista, e as relações amorosas não se encontram no cerne do discurso poético. A figura masculina, que aparece na obra de Gilka Machado ora sendo representada com desejo amoroso, ora como símbolo opressor, aqui surge longe da ideia de uma possível união afetiva. Projetado para fora de si, o sujeito lírico dessa obra aborda as questões da sociedade, olha para a indústria cultural, se debruça sobre os ritos culturais da cidade do Rio de Janeiro, homenageia a cultura afrodescendente da Bahia e os mocambos do Recife. O poema "O mundo necessita de poesia" integra a obra Sublimação.

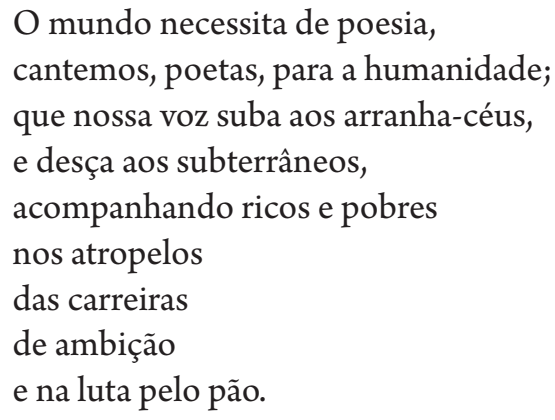


Lavemo-nos das máscaras histriônicas, tenhamos a coragem

de propalar a existência externa

do sentimento;

ponhamos termo

a esses malabarismos

de palhaços falsos

da modernidade,

permanecendo diferentes,

diante da multidão

insensibilizada

enferma.

A humanidade quer rir de tudo,

porém é alvar sua gargalhada.

Foge das tristezas,

mas paira ausente

em meio aos prazeres,

indumentária,

mais vergonha me vinha

de mim mesma,

por tal maneira

transfigurada.

As horas passavam velozes

e eu cantava,

supondo que ao meu canto

é que a Terra girava.

(MACHADO, 2017, p. 308-310)

A partir desse poema, podemos notar que Sublimação toma outra estética e ganha uma forma bastante moderna. Surge o uso do verso livre, das estrofes sem rimas, de um ritmo cadenciado, da simplicidade temática; passa-se a comunicar com maior clareza. Sem abandonar o tema do feminino e suas questões de gênero, o sujeito lírico parece ser a 
mulher consciente, que luta pelas classes oprimidas e, com uma linguagem mais expansiva, parece querer se fazer mais bem compreendida por seus "companheiros e companheiras".

Se retomarmos as ideias de Adorno sobre a lírica, podemos entender que a linguagem cria um elo entre lírica e sociedade, sem que seja necessário recorrer à matéria ou à "experiência exterior" da qual trata o poema. Assim, podemos perceber o que existe de humano na lírica através da linguagem, pois a linguagem continua sendo o meio dos conceitos por estabelecer uma "inelutável referência ao universal e à sociedade" (ADORNO, 1980, p. 74).

As mais altas composições líricas são, por isso, aquelas nas quais o sujeito, sem qualquer resíduo da mera matéria, soa na linguagem, até que a própria linguagem ganha voz. $\mathrm{O}$ auto-esquecimento do sujeito, que se entrega à linguagem como a algo objetivo, é o mesmo que o caráter imediato e involuntário de sua expressão: assim a linguagem estabelece a mediação entre lírica e sociedade no que há de mais intrínseco. (ADORNO, 1980, p. 74)

Seguindo o pensamento de Adorno (1980), a experiência social e individual pode interferir na lírica, pois a lírica não consegue se manter apenas no plano da subjetividade e, assim, atua construindo uma mediação entre a obra e a experiência social. O sujeito lírico cede lugar à linguagem para que essa fale ao poema. Quando dizemos que o sujeito de Gilka Machado em "O mundo necessita de poesia" - e, por extensão, em todos os poemas de Sublimação - busca se comunicar com um maior número de leitores, estamos indo ao encontro desse pensamento que atribui à linguagem a comunicação das experiências individuais. Dessa forma, parece possível que o sujeito se insira no âmbito da identidade e também no plano da alteridade, quando a poeta se manifesta por um lirismo peculiar ao "ser e estar" no mundo. Olhando por esse viés, notamos que o sujeito lírico pode incluir suas experiências ao falar de si, sendo individual, mas pode também incluir o outro, compreendendo o universal. 
Ao incluir o outro, a lírica toma uma atitude universal, que é a condição que, desde Hegel (RAMOS, 1986), se expressa na consciência da subjetividade lírica. Falando pela voz do indivíduo, a linguagem passa a ser parte de todos os homens.

A arte da poesia lírica avança certamente para situações determinadas, no interior das quais permanece facultado ao sujeito lírico introduzir uma grande multiplicidade do conteúdo em seu sentimento e reflexão; todavia, neste gênero, é sempre a forma do interior que fornece o tipo fundamental e já desse modo exclui de si a ampla intuitibilidade da realidade exterior. (RAMOS, 1983, p. 44)

A universalidade não é tratada como metafísica, mas implicada no processo histórico-social por via da mediação da subjetividade. A atividade lírica, a qual menciona Adorno (1993), pode estar determinada por uma sociedade que reivindica a individualidade e imprime ao sujeito seu direito ao mergulho na própria individuação.

Historicamente, essa marca pode ser pensada como um privilégio da voz lírica que irrompe, de muitos modos, o desejo substancial de que nela se revele a "corrente subterrânea" da voz coletiva para que outros sujeitos se reconheçam ${ }^{1}$. Quando o sujeito lírico de "O mundo necessita de poesia" inicia seu discurso exaltando uma necessidade coletiva e incita que "nossa voz suba aos arranha-céus e desça aos subterrâneos", contempla um mundo de "ricos e pobres" que vivem pela "luta do pão". No poema parece ficar claro que a lírica alia a individuação do sujeito, capaz de perceber "as horas que passam velozes", a uma voz lírica que, quando se põe a cantar, supõe a própria Terra que gira, transformando, assim, a visão restrita de si mesma à coletividade do social.

Ainda seguindo Adorno (1980), podemos pensar que esse estado social experimentado pela voz lírica individual, como alguém que se sente "nua diante do mundo", apresenta uma formação lírica que pretende se libertar de toda opressão, como um eu liberto, oposto ao coletivo, um eu

1 Cf. ADORNO, 1980, p. 199-200. 
que reverbera sobre si mesmo e ecoa na linguagem para apontar o sentido coletivo e para desejá-lo como o seu ideal, a sua utopia. Tal reverberação da voz lírica, quando atentamos ao poema, nos permite pensar que seu significado se encontra na relação histórica do sujeito com a objetividade social.

Contrário a essa posição, Friedrich (1991), teórico que estudou as poéticas de Baudelaire, Rimbaud e Mallarmé, apresenta um ponto de vista anti-histórico ao evidenciar que a lírica moderna se tornou centrada em si mesma e independente de qualquer vínculo com a realidade. Pela leitura de Friedrich, entendemos que a lírica, a partir de meados do século XIX, perdeu sua função de representação e sua relação, de qualquer maneira que fosse, com um conteúdo ligado à realidade exterior: "Um traço fundamental da poesia moderna é seu afastamento cada vez mais decidido da vida natural" (FRIEDRICH, 1991, p. 116). Podemos refletir se dentro do fato de a poesia fazer uso da linguagem estaria também lançada a voz de um sujeito com reflexos sociais, sendo a língua um instrumento de socialização e, assim, tendo ela também implicações relacionadas aos aspectos sociais.

Na contramão da ideia de Friedrich (1991), encontramos os argumentos de Hamburger (2007) e Berardinelli (2007), que, ao encontro de Adorno, apresentam que a total despersonificação da arte seria uma espécie de desumanização, sendo esse movimento algo impossível de ocorrer, haja vista a poesia ser construída por seres humanos, seres sociais e agentes de uma sociedade. Além disso, para tais teóricos, esse fenômeno não é comumente encontrado no mundo da criação poética que corresponde à lírica moderna fora das páginas que pontuam a estrutura de Friedrich.

Assim, propomos que Gilka Machado, indo ao encontro do pensamento de Hamburger (2007), também pode ser considerada uma das representantes da poesia moderna, capaz de manifestar uma preocupação pela humanidade como um todo, e de modo ainda mais intenso que no Romantismo. Sendo a poesia de Gilka Machado, em Sublimação, menos confessional e mais interessada por sua própria individualidade, ela pôde, 
assim, se aproximar da sociedade, como indivíduo semelhante aos seus leitores.

Gilka Machado, como uma poeta moderna, apresenta a natureza humana de uma operária da poesia, e não como uma representante ou líder de um movimento. Assim, na condição de irmã de toda uma humanidade, seus versos efetivam o elo entre lírica e sociedade por meio de uma voz que pretende e consegue ser ouvida por seus pares, livre do fardo da poesia pura, hermética, e do obscurantismo comunicativo.

Quando pensamos nesse tipo de lírica, retomamos o pensamento de Friedrich (1991) e percebemos uma oposição com as ideias de Adorno (1980), que são evidenciadas aqui com algumas ressalvas elencadas por Berardinelli (2007). Para o teórico italiano, Adorno identifica, assim como Friedrich (1956), a poesia moderna como "a lírica mais inclinada a não transparência comunicativa" e ao "phatos da distância" e a "sua leitura da situação e da relação lírica-sociedade segue a direção contrária” (ADORNO, 1993, p. 98). Para Berardinelli (2007, p. 35-36), Friedrich (1991) interpreta como potência da linguagem a capacidade da lírica de "destruir" o real ou de servir-se dele com "[...] absoluta liberdade para os próprios fins estéticos”, e em Adorno esses termos aparecem como termos invertidos.

A liberdade absoluta, a qual é compreendida pelo uso de uma “linguagem autônoma”, é, para Adorno (1980, p. 122), uma constrição que impõe a determinação social e histórica. Para Berardinelli (2007, p. 37), o que distancia e se opõe ao mundo poético e ao mundo real é, também, o que os enlaça em um "vínculo mortal", e esse vínculo pode ser ao mesmo tempo estético e histórico, pois determina as formas não comunicativas e antirrealistas da lírica moderna ao denunciar o estado das coisas na sociedade contemporânea.

Em “O mundo precisa de poesia”, o sujeito lírico de Gilka Machado denuncia uma "humanidade que quer rir de tudo", mas seu riso leva à hipocrisia de uma sociedade desigual, que "foge das tristezas" e "paira ausente em meio aos prazeres". Dessa forma, a voz lírica do poema se enlaça ao "vínculo mortal" e percorre um caminho estético e histórico, 
onde se encontram as mazelas sociais e, ao mesmo tempo que surge com um vocabulário simples, apresenta uma linguagem poética múltipla em sentidos. Adorno (1980, p. 78) “[...] observa que o sujeito que representa um sujeito coletivo, é muito mais universal e, assim, mantém vínculo com a realidade social", mesmo quando não trata diretamente dessa realidade, pois os poemas, como objetos líricos, inerentes a qualquer tipo de composição de linguagem, merecem ser interpretados a fim de que se possa identificar uma interpenetração de ambos.

A interpenetração à qual se refere Adorno se configura quando um "[...] poema lírico captura realmente, em seus limites, as badaladas do tempo histórico” (ADORNO, 1980, p. 78) e, assim, encaminhandonos para o desfecho desta reflexão, pensamos na linguagem como um elemento em que a voz coletiva se permite falar e ouvir. Um poema, como objeto estético que pertence à linguagem, garante o elo entre lírica e realidade social a partir da voz de um sujeito poético sensível ao contexto. Dessa forma, podemos pensar que a verdade da lírica de Gilka Machado consiste em denunciar os abusos de um território fechado à condição das mulheres, que ora pode ser visto como uma tentativa de acessar seu próprio corpo, ora como sua própria busca em encontrar a sua voz na poesia.

THE WORLD NEEDS POETRY: THE LYRICISM AND SOCIETY IN GILKA MACHADO'S WORK

\section{AbStract}

We have analyzed the lyrical subject in Gilka Machado's work in two moments: in the poems "Ser mulher..." published in her debut work, Cristais Partidos, from 1915, and "O mundo necessita de poesia", which integrates her last work, Sublimação, from 1938. When observing the pertinent relations between lyricism and society, we explored the social and aesthetic questions that guided the poet's trajectory. Thus, we broadened the research on Gilka Machado's work, contributing to the rescue of the poet in the history of Brazilian literature.

KeYwORDs: Poetry. Gilka Machado. Female autorship. 
EL MUNDO NECESITA POESÍA: LA LÍRICA Y LA SOCIEDAD EN LA OBRA DE Gilka Machado

RESUMEN

Este artículo pretende analizar el tema lírico entendido en la obra de Gilka Machado en dos momentos: en los poemas "Ser Mulher ..., publicados en su obra debut, Cristales rotos, de 1915, y "El mundo necesita poesía ", Que integra su última obra, Sublimação, de 1938. Al identificar las imágenes y observar las relaciones pertinentes entre la lírica y la sociedad, la obra se propone explorar las cuestiones sociales y estéticas que guiaron la trayectoria de la poeta. De esta manera, queremos ampliar la investigación sobre su obra, contribuyendo al rescate de la poeta en la historia de la literatura brasileña.

Palabras Clave: Poesía. Gilka Machado. Autoría femenina.

\section{REFERÊNCIAS}

ADORNO, Theodor. Lírica e sociedade. In: BENJAMIN, W. et al. Textos escolhidos. Tradução José Lino Grünewald et al. São Paulo: Abril Cultural, 1980. (Coleção Os pensadores).

BERARDINELLI, Alfonso. Da poesia à prosa. Tradução Maurício Santana Dias. São Paulo: Cosac Naify, 2007.

BOURDIEU, Pierre. As regras da arte: gênese e estrutura do campo literário. São Paulo. Companhia das Letras, 1996.

FOUCAULT, Michael. A ordem do discurso. 15. ed. São Paulo: Loyola, 2007.

FRIEDRICH, Hugo. Estrutura da lírica moderna. Tradução Marise Curioni. São Paulo: Duas Cidades, 1991.

GOTLIB, Nádia. Com Gilka Machado, Eros pede a palavra. 2016. https://www. labrys.net.br/labrys29/arte/nadia.htm Acesso em: 17 nov. 2021.

HAMBURGER, Michael. A verdade da poesia. Tradução Alípio Correia de Franca Neto. São Paulo: Cosac Naify, 2007.

MACHADO, Gilka. Poesia completa. São Paulo: Selo Demônio Negro: 2017. 
MASSUELA, Amanda. Obra de Gilka Machado volta a circular após 24 anos fora de catálogo. Cult, 2017. Disponível em: https://revistacult.uol.com.br/ home/obra-de-gilka-machado-volta-a-circular/ Acesso em: 17 nov. 2021.

PAZ, Octavio. A dupla chama: amor e erotismo. Tradução Wladir Dupont. São Paulo: Siciliano, 1994.

PAZ, Octavio. A outra voz. Tradução Wladyr Dupont. São Paulo: Editora Siciliano, 1990.

RAMOS, Cesar Augusto (org.). Liberdade subjetiva e Estado na filosofia política de Hegel. Curitiba: Editora da UFPR, 1986.

RICOUER, Paul. A metáfora viva. Tradução Joaquim Torres Costa e António Magalhães. Porto: Rés, 1978.

SABATO, Ernesto. O escritor e seus fantasmas. Rio de Janeiro: Francisco Alves, 1982.

STAIGER, Emil. Conceitos fundamentais da poética. Rio de Janeiro: Tempo Brasileiro, 1975.

VALÉRY, Paul. Variedades. Tradução Maiza Martins de Siqueira. São Paulo: Iluminuras, 1991.

Submetido em 31 de agosto de 2021

Aceito em 22 de novembro de 2021

Publicado em 30 de janeiro de 2022 